OPEN ACCESS

Edited by:

Fagen Wang,

Jiangsu University, China

Reviewed by:

Weijie Cai,

Dalian Polytechnic University, China Chuanhui Zhang,

Qingdao University, China

Congming Li,

Taiyuan University of

Technology, China

${ }^{*}$ Correspondence:

Hui L

lihui@shnu.edu.cn

Yu Zhao

313769727@qq.com

Specialty section: This article was submitted to

Nanoscience,

a section of the journa

Frontiers in Chemistry

Received: 11 February 2020 Accepted: 09 March 2020

Published: 23 April 2020

Citation:

Wang G, Liang Y, Song J, Li H and Zhao Y (2020) Study on High Activity

and Outstanding Stability of

Hollow-NiPt@SiO 2 Core-Shell

Structure Catalyst for DRM Reaction.

Front. Chem. 8:220.

doi: $10.3389 /$ fchem.2020.00220

\section{Study on High Activity and Outstanding Stability of Hollow-NiPt@SiO 2 Core-Shell Structure Catalyst for DRM Reaction}

\author{
Guangying Wang ${ }^{1}$, Yan Liang ${ }^{1}$, Jian Song ${ }^{1}$, Hui Li ${ }^{2 *}$ and Yu Zhao ${ }^{1 *}$ \\ ${ }^{1}$ Anhui Yuanchen Environmental Protection Technology Co., Ltd., Hefei, China, ${ }^{2}$ College of Life and Environmental Sciences, \\ Shanghai Normal University, Shanghai, China
}

A neoteric hollow-NiPt@SiO 2 core-shell structure catalyst with 7-nm-sized hollow NiPt alloy nanoparticle (NP) packaged by $\mathrm{SiO}_{2}$ shell was prepared by a classic Stober method. Compared with hollow-NiPt/ $\mathrm{SiO}_{2}$ supported catalyst, the hollow-NiPt@ $\mathrm{SiO}_{2}$ core-shell catalyst exhibited better activity and thermal stability in dry reforming of methane $\left(\mathrm{CH}_{4}\right)$ (DRM) with $\mathrm{CO}_{2}$ reaction, with $\mathrm{CH}_{4} / \mathrm{CO}_{2}$ conversion to $97 \%$ and service life to $200 \mathrm{~h}$ at $800^{\circ} \mathrm{C}$, respectively. In addition, the activity and stability of core-shell catalysts with different nuclei were tested. In contrast to the continuous deactivation of the supported catalyst, all the core-shell catalysts were able to maintain stability for $200 \mathrm{~h}$, and the activity sequence was Hollow-NiPt $>$ NiPt NPs $>$ Pt NPs $>$ Ni NPs. By characterization, we learned that hollow structure had an inner surface and thus had a larger active specific surface area than NP structure. In addition, NiPt NPs had better activity than Ni NPs and Pt NPs because Ni and Pt formed as alloy in NiPt NPs. Therefore, the efficient and thermally stable hollow-NiPt@ $\mathrm{SiO}_{2}$ core-shell catalyst has a promising application prospect in DRM reaction and can make a considerable contribution to the sustainable use of energy.

\begin{abstract}
Keywords: hollow-NiPt@SiO ${ }_{2}$ core-shell catalyst, renewable energy, dry reforming of methane $\left(\mathrm{CH}_{4}\right)$ (DRM)
\end{abstract} reaction, NiPt alloy, sintering resistance of $\mathrm{SiO}_{2}$

\section{INTRODUCTION}

Coal and oil are the most important energy consumed in the world; fossil fuels accounted for $85 \%$ of global energy consumption in 2018. When fossil fuels are used, a large amount of greenhouse gas- $\mathrm{CO}_{2}$ will be produced, accompanied by the generation of polluted flue gas, leading to increasingly serious environmental pollution (Michael et al., 1993; Gurney et al., 2009). On the other hand, coal and oil are non-renewable resources, and the reserves are limited and dwindling. The global fossil-energy revolution has begun, with abundant and cheap natural gas accounting for a growing share of the world's energy consumption. With the breakthrough of shale gas exploitation technology, the application of natural gas has become a worldwide research hotspot in recent years (Wu et al., 2016; Middleton et al., 2017). As the main component of natural gas, there are direct and indirect methods for effective use of methane $\left(\mathrm{CH}_{4}\right)$ (Reddy et al., 2013). Direct transformation of $\mathrm{CH}_{4}$ includes oxidation coupling, chlorination coupling, and direct dehydrogenation (Otsuka et al., 1987; Sun and Klabunde, 1999; Zhang et al., 2015). The simple conversion process has 
potential theoretical advantages. However, due to the difficulty of activation of $\mathrm{CH}_{4}$ molecule, direct conversion is usually conducted under harsh conditions of high temperature, high pressure, and high energy consumption. In addition, the complex product composition greatly limits the use of $\mathrm{CH}_{4}$. Indirect transformation of $\mathrm{CH}_{4}$ includes steam reforming, $\mathrm{CO}_{2}$ dry reforming, and partial oxidation, etc. (Iulianelli et al., 2016; Amin et al., 2017; Parola et al., 2018). $\mathrm{CH}_{4}$ and $\mathrm{CO}_{2}$ can be catalytic converted to syngas $\left(\mathrm{CO}\right.$ and $\left.\mathrm{H}_{2}\right)$ by dry reforming of $\mathrm{CH}_{4}$ (DRM) reaction. In general, syngas can be converted to liquid fuel by Fischer-Tropsch process or removed from $\mathrm{CO}$ via pressure swing adsorption (PSA) to obtain high purity hydrogen (99.999\%) which can be used in proton exchange membrane fuel cell (PEMFC) (Miura et al., 2012, 2013; Qiu et al., 2017; Rosli et al., 2017). In recent years, DRM reaction has made significant progress in industrial applications, but large-scale commercial distribution has yet to address the following issues: catalyst thermal stability and carbon resistance (Bian et al., 2016).

The DRM reaction catalysts can be classified into noble metal catalysts and non-noble metal catalysts according to the active metal component. Noble metal catalysts such as Pt, Pd, Rh, and $\mathrm{Ru}$ have high activity, high stability, and excellent carbon resistance in DRM reaction (Graf et al., 2007; Özkara-Aydinoglu et al., 2009). Nagaoka et al. (2001a) loaded Pt on $\mathrm{ZrO}_{2}$ and $\mathrm{Al}_{2} \mathrm{O}_{3}$, respectively, to study the effect of support on DRM reaction, and results showed that $\mathrm{ZrO}_{2}$ had better performance and could run for $500 \mathrm{~h}$ without loss of activity. Nagaoka et al. (2001b) studied the high-pressure reaction performance of $\mathrm{Ru} / \mathrm{TiO}_{2}$ catalyst for DRM reaction and found that the $2 \% \mathrm{Ru} / \mathrm{TiO}_{2}$ catalyst showed excellent carbon resistance at $750^{\circ} \mathrm{C}$ and $2 \mathrm{MPa}$ pressure. However, the high price and scarce resources of noble metal limit its industrial application prospect, while non-noble metals such as $\mathrm{Ni}, \mathrm{Co}$, and $\mathrm{Fe}$ also show high initial activity (Nagaoka et al., 2003; Guo et al., 2004; Wang et al., 2011; Djinović et al., 2012). The $\mathrm{Ni}$ is relatively cheap and widely used in industrial hydrogen production. However, the most serious issue of Ni-based catalyst is easy to sinter and carbon deposit, leading to deactivation of the catalysts. In order to solve this problem, Ni was modified by using the carbon resistance of noble metal. The work of García-Diéguez et al. (2010) showed that the Pt addition in $\mathrm{Ni} / \mathrm{Al}_{2} \mathrm{O}_{3}$ formed the Pt-Ni alloy active site which could promote the reduction of $\mathrm{NiO}$ to $\mathrm{Ni}$ and inhibit the formation of the inactive site of $\mathrm{NiAl}_{2} \mathrm{O}_{4}$. Liu et al. (2010) showed that adding a small amount of $\mathrm{Pd}$ or Pt to Ni/MCM-41 increased the dispersion and reductivity of $\mathrm{NiO}$, although no alloy formation was observed. Nowosielska et al. (2009) found that the DRM activity of $\mathrm{Ni}-\mathrm{Rh}$ was better than the single metal $\mathrm{Ni}$ due to the formation of Ni-Rh alloy active site in the catalyst when studying the modification effect of $\mathrm{Rh}$ on $\mathrm{Ni} / \mathrm{Al}_{2} \mathrm{O}_{3}$ and $\mathrm{Ni} / \mathrm{SiO}_{2}$. In addition, Guczi et al. (2010) concluded that Au can also effectively improve the DRM activity and stability of $\mathrm{Ni} / \mathrm{Al}_{2} \mathrm{O}_{3}$ as additive.

Due to the rarity of noble metals, how to use them efficiently is the focus. The general method is to reduce the size of the nanoparticles (NPs) (Qiao et al., 2011) or to obtain a special morphology catalyst. Compared with solid NPs, hollow metal nanospheres have become a very effective material to improve the utilization of noble metals due to the advantages of incomparable surface area, lower density, and metal consumption (Kim et al., 2002; Chen et al., 2005; Zhou et al., 2007; Li et al., 2008, 2010). Hollow alloy or bimetallic materials are hot topics in the field of materials research. Chen et al. (2007) synthesized Co-Pt hollow spheres with adjustable composition by an one-step synthesis method; in comparison with Pt NPs, the hollow material showed enhanced electrocatalytic activity toward methanol oxidation. PdCo bimetallic hollow nanospheres synthesized in polyethylene glycol solution was applied to catalysis of the Sonogashira reaction, which displayed obvious advantages of environmentally friendly reaction condition, good catalyst recyclability, simple experimental operation, and high yields (Li et al., 2006). Li et al. (2011) prepared hollow Ni-Pt alloy nanospheres with alterable particle size by an element substitution method, the hollow alloy nanoparticle exhibits higher activity, enhanced selectivity, and better stability than the solid Pt NP on p-chloronitrobenzene hydrogenation reaction.

Since the DRM reaction temperature is required to be very high, usually above $700^{\circ} \mathrm{C}$, the sintering resistance ability of the catalyst is also significant. The thermal stability of supported catalyst could usually be improved by increasing the metalsupport interaction. However, at such an extremely high DRM reaction temperature, the regular supported catalysts could not completely prevent sintering through such metal-support interaction. It is a reliable strategy to improve the catalyst thermal stability to anchor the metal to the center of the support or between the interlayer by sandwiched structure or coreshell structure. Zhao et al. (2018a) prepared $\mathrm{Al}_{2} \mathrm{O}_{3} / \mathrm{Ni} / \mathrm{Al}_{2} \mathrm{O}_{3}$ sandwiched catalyst by depositing $\mathrm{Al}_{2} \mathrm{O}_{3}$ thin films on $\mathrm{Al}_{2} \mathrm{O}_{3}$ support to coat Ni NPs through atomic layer deposition (ALD) method, and this catalyst exhibited excellent thermal stability, running stably for over $400 \mathrm{~h}$ without activity loss. Core-shell catalysts also maintain outstanding thermal stability in DRM reactions (Zhao et al., 2018b). At present, high-stability coreshell catalysts with various metals ( $\mathrm{Ag}, \mathrm{Au}, \mathrm{Pt}, \mathrm{Ni}$, etc.) have been reported except those with hollow-NiPt as the core (Radloff and Halas, 2001; Chen et al., 2013).

Herein, we reported a novel hollow-NiPt@SiO ${ }_{2}$ core-shell catalyst, which performed excellent activity and operated steadily for $200 \mathrm{~h}$. The hollow-NiPt NPs were prepared by a modified galvanic replacement method as shown in Figure 1. The premise of replacement reaction is oxidation reduction potential.

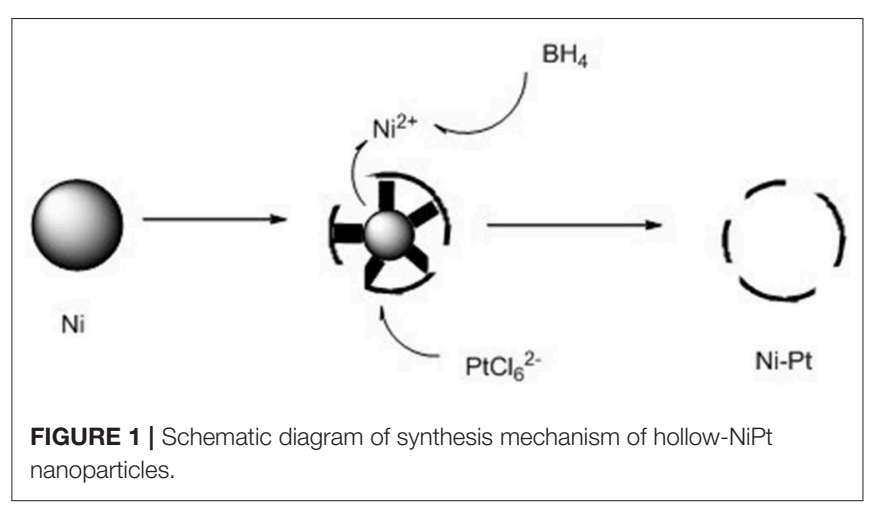


The corresponding standard electrode potentials are: $\mathrm{Ni}^{2+} / \mathrm{Ni}$, $-0.250 \mathrm{eV} ; \mathrm{PtCl}_{6}^{2-} / \mathrm{Pt}, 0.735 \mathrm{eV}$. Due to the rapid replacement reaction, platinum atoms nucleate rapidly on the surface of the $\mathrm{Ni}$ $\mathrm{NP}$ to form smaller particles. Meanwhile, the precipitated $\mathrm{Ni}^{2+}$ is rapidly reduced by $\mathrm{BH}_{4}^{-}$and redeposited on the surface of Ni NP. Because the reductant is added drop by drop, the limited $\mathrm{PtCl}_{6}^{2-}$ will be dispersed on multiple Ni NPs, and the porous structure on the surface makes the inner Ni metal can be continuously replaced to form the ion diffusion, finally deposited on the outer surface, forming a porous shell structure. Compared with $\mathrm{Ni}$, $\mathrm{Pt}$, and NiPt solid NPs, hollow NPs had better activity, and the stability of core-shell catalysts are better than that of support catalysts. It is clear that the hollow-NiPt catalyst is a suitable catalyst for converting $\mathrm{CH}_{4}$ by DRM into syngas, and the $\mathrm{SiO}_{2}$ coating provides very reliable thermal stability for the catalyst.

\section{EXPERIMENTAL SECTION}

\section{Catalyst Preparation}

\section{Preparation of Hollow-NiPt@SiO}

$\mathrm{NiCl}_{2} \cdot 6 \mathrm{H}_{2} \mathrm{O} 0.068 \mathrm{~g}$ and poly(vinylpyrrolidone) (PVP; $\mathrm{MW}=$ 40,000) $0.2 \mathrm{~g}$ were dissolved in $400 \mathrm{ml}$ deionized water. The mixed solution was sonicated for $15 \mathrm{~min}$ and then purified with $\mathrm{N}_{2}$ for another $15 \mathrm{~min}$. $\mathrm{NaBH}_{4} 80 \mathrm{ml}(80.0 \mathrm{mg})$ solution was added to the above solution drop by drop and stirred at $25^{\circ} \mathrm{C}$ for $30 \mathrm{~min}$. After pumping $80 \mathrm{ml}$ of $\mathrm{K}_{2} \mathrm{PtCl}_{6}(65.6 \mathrm{mg})$ solution through a peristaltic pump at a speed of $5.0 \mathrm{ml} \cdot \mathrm{min}^{-1}$ into the above solution, continue stirring for $30 \mathrm{~min}$ to get hollow$\mathrm{NiPt}$ NPs. At room temperature, the resulting 480-ml solution containing hollow-NiPt NPs was mixed with $1,000 \mathrm{ml}$ ethanol solution containing $150 \mu \mathrm{l}$ tetraethyl orthosilicate (TEOS, 98\%), and then $10 \mathrm{ml}$ aqueous ammonia solution was added. After stirring for $6 \mathrm{~h}, 200 \mathrm{ml}$ toluene was added as settler. The sediment in the bottom was centrifuged and washed with ethanol three times to obtain hollow-NiPt@SiO 2 NPs.

\section{Preparation of $\mathrm{Ni@SiO}$, $\mathrm{Pt} @ \mathrm{SiO}_{2}$, and NiPt@SiO}

$\mathrm{Ni}$ and Pt NPs with particle sizes of $\sim 7 \mathrm{~nm}$ were synthesized by adding $0.77 \mathrm{~g}$ nickel(II) acetylacetonate [Ni(acac) $2,95 \%$ ] or $1.17 \mathrm{~g}$ platinum(II) acetylacetonate [Pt(acac) $2,97 \%$ ], $1.1 \mathrm{ml}$ tributylphosphate (TBP, 97\%), and $2.3 \mathrm{ml}$ trioctylphosphine (TOP, 90\%) to $20 \mathrm{ml}$ oleylamine (OAm, 70\%) solution. After being treated at $120^{\circ} \mathrm{C}$ for $2 \mathrm{~h}$ in a vacuum oven to remove water and oxygen, the mixture was heated to $220^{\circ} \mathrm{C}$ and kept heated for $1 \mathrm{~h}$ at this temperature. When the solution was cooled to room temperature, the solid product was separated by centrifugation and washed several times with a mixture of ethanol and cyclohexane. The resulting NPs were dissolved in 50 $\mathrm{ml}$ cyclohexane.

NiPt NPs with a particle size of about $7 \mathrm{~nm}$ were obtained by co-reduction method with organic reductant. $\mathrm{Ni}(\mathrm{acac})_{2} 0.77 \mathrm{~g}$, $\mathrm{Pt}(\mathrm{acac})_{2} 1.17 \mathrm{~g}$, and 1,2-hexadecanediol $0.78 \mathrm{~g}$ were added to the mixture of $3.2 \mathrm{ml}$ oleic acid (OAc), $4.6 \mathrm{ml} \mathrm{TOP}$, and $10 \mathrm{ml}$ OAm. After the same pretreatment with the removal of water and oxygen as in the previous preparation of Ni and Pt NPs, the solution temperature was controlled to $90^{\circ} \mathrm{C}$, and $6 \mathrm{ml} \mathrm{OAm}$ [containing $0.79 \mathrm{~g}$ borane tributylamine complex (BTB, 97\%)] was quickly added and stirred for $1 \mathrm{~h}$. In the same way that $\mathrm{Ni}$ and Pt NPs were collected, the resulting NiPt NPs was dissolved in $50 \mathrm{ml}$ of cyclohexane.

The Ni@SiO 2 , Pt@SiO 2 , and $\mathrm{NiPt} @ S i O_{2}$ core-shell catalysts were all synthesized by a reverse microemulsion method.
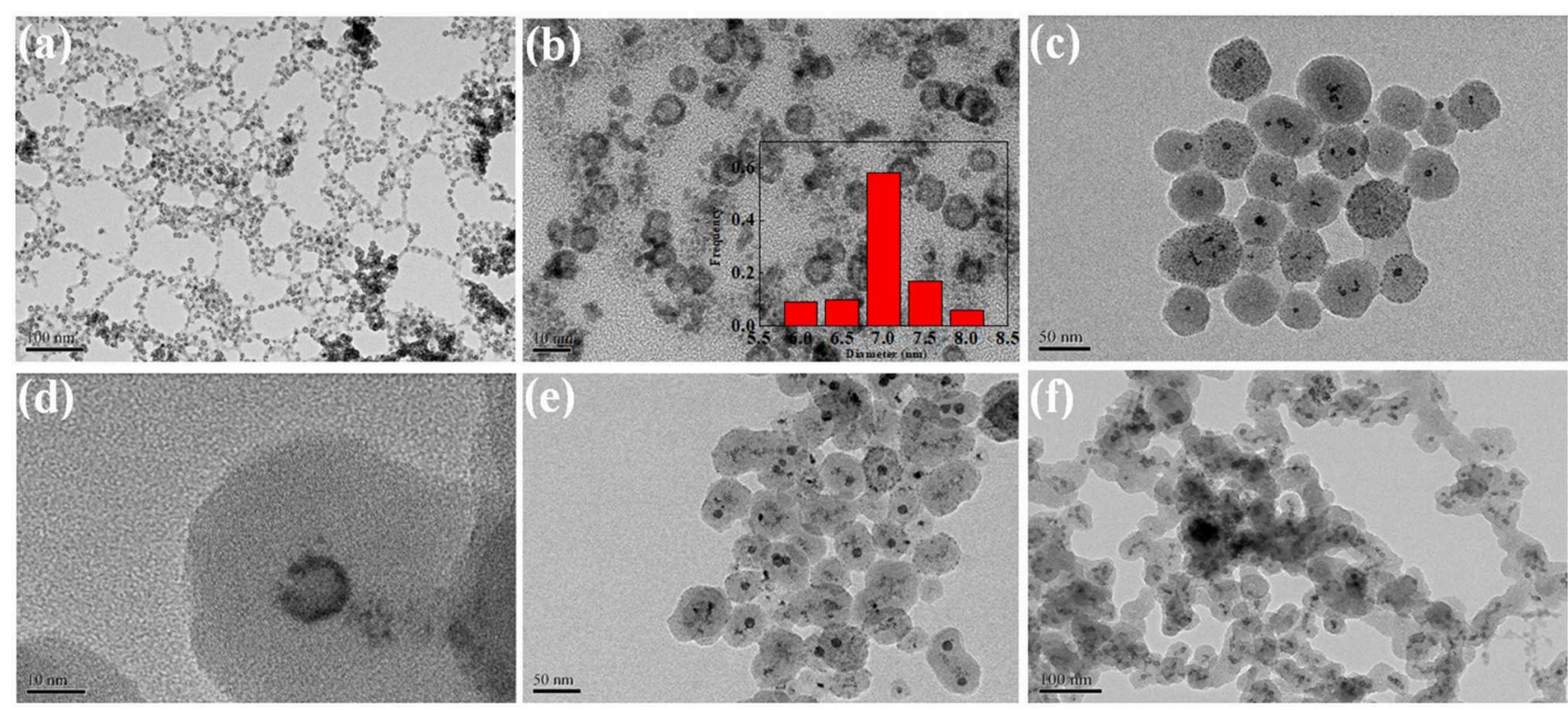

FIGURE 2 | Transmission electron microscopy (TEM) images of (a) Hollow-NiPt; (b) amplification of Hollow-NiP; (c) Hollow-NiPt@SiO 2 before calcination; (d) amplification of Hollow-NiPt@SiO 2 before calcination; (e) Hollow-NiPt@SiO 2 after calcination and subsequent reduction; (f) supported Hollow-NiPt/SiO 2 after reduction. The attached are the particle size distribution patterns. 
Organic phase $(50 \mathrm{ml}$ cyclohexane), aqueous phase $(2.0 \mathrm{ml}$ aqueous ammonia solution), and surfactant ( $16 \mathrm{ml}$ igepal CO630) were stirred for $10 \mathrm{~min}$ to form a reverse microemulsion. The resulting microemulsion was then mixed with $50 \mathrm{ml}$ cyclohexane containing $3.0 \mathrm{mmol}$ metal NPs. After $30 \mathrm{~s}$ of rapid stirring, $2.0 \mathrm{ml}$ tetramethyl orthosilicate (TMOS, 98\%) and $2.0 \mathrm{ml}$ octadecyltrimethoxysilane ( $\left.\mathrm{C}_{18} \mathrm{TMS}, 90 \%\right)$ were added as silicon sources. After stirring for $30 \mathrm{~min}$ at room temperature, $10 \mathrm{ml}$ methanol was added as settling agent, and the solid product was separated by centrifugation and washed with ethanol several times.

\section{Preparation of Hollow-NiPt/SiO 2}

The supported hollow- $\mathrm{NiPt} / \mathrm{SiO}_{2}$ catalyst was prepared by impregnation method. The $\mathrm{SiO}_{2}$ nanospheres was prepared by the same microemulsion method as above, only without the addition of metal NPs. Hollow-NiPt NPs were dispersed in water as the impregnation liquid.

All catalysts were calcined at $800^{\circ} \mathrm{C}$ for $4 \mathrm{~h}$ prior to activity testing.

\section{Catalyst Characterization}

Metal contents in catalysts were determined by inductively coupled plasma optical emission spectrometry (ICP-OES; Varian VISTA-MPX). We used transmission electron microscopy (TEM; JEOL JEM2100) to observe catalyst microstructure. The catalyst reduction performance was tested by temperature programmed reduction (TPR) on PCA-1200, $0.1 \mathrm{~g}$ catalyst was heated to $1,000^{\circ} \mathrm{C}$ at a heating rate of $5^{\circ} \mathrm{C} / \mathrm{min}$. The carbon deposition of deactivated catalyst was analyzed by Perkin-Elmer, Pyris Diamond TG/DTA instrument. CO chemisorption was used to analyze the metal dispersion.

\section{Activity Test}

The DRM reaction was performed in a fixed-bed reactor (inner diameter $=10 \mathrm{~mm}$ ). Before reaction, the catalysts should be reduced under the condition of $10 \% \mathrm{H}_{2} / \mathrm{N}_{2}(50 \mathrm{ml} / \mathrm{min})$, and then the reduced gas should be switched to $\mathrm{N}_{2}$ for $10 \mathrm{~min}$ before the reaction gas $\left(\mathrm{CH}_{4} / \mathrm{CO}_{2} / \mathrm{N}_{2}=1: 1: 1\right)$ is vented into the reactor. The reaction products were dehydrated and analyzed by an online gas chromatograph (Agilent 7890B GC) with a packed column (TDX-01) and a thermal conductivity detector (TCD). The active data were collected $2 \mathrm{~h}$ after the reaction began. The conversions of $\mathrm{CH}_{4}$ and $\mathrm{CO}_{2}$ were calculated by the following equations:

$$
\begin{aligned}
& X_{\mathrm{CH}_{4}}=\frac{F_{\mathrm{CH}_{4}, \text { in }}-F_{\mathrm{CH}_{4}, \text { out }}}{F_{\mathrm{CH}_{4} \text {,in }}} \times 100 \\
& X_{\mathrm{CO}_{2}}=\frac{F_{\mathrm{CO}_{2} \text {, in }}-F_{\mathrm{CO}_{2} \text {,out }}}{F_{\mathrm{CO}_{2} \text {,in }}} \times 100
\end{aligned}
$$

$$
F_{i}=F_{\text {total }} \times C_{i}
$$

where $\mathrm{X}, \mathrm{F}$, and $\mathrm{Ci}$ are conversion, selectivity, gas flow rate, and molar fraction of $\mathrm{i}$ in the feed gas or the effluent gas, respectively.

\section{RESULTS AND DISCUSSION}

\section{Structural Characteristics}

Figure 2 showed the TEM of core-shell and supported structure hollow-NiPt catalyst. It can be seen from the TEM images in Figures 2a,b that the hollow-NiPt NPs are present in the form of hollow nanospheres with a particle size of about $7 \mathrm{~nm}$. In

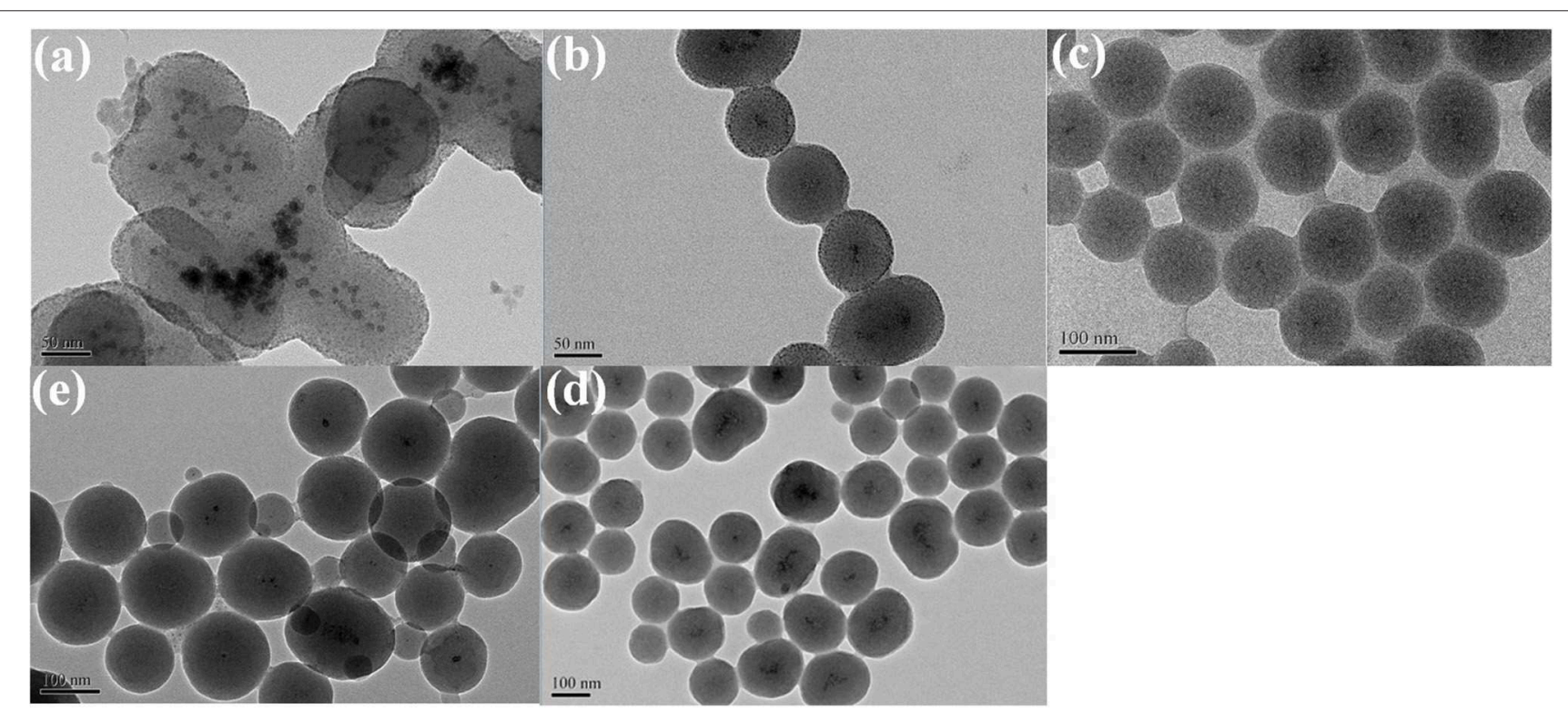

FIGURE 3 | Transmission electron microscopy (TEM) images of hollow-NiPt@SiO 2 with different tetraethyl orthosilicate (TEOS) addition: (a) $100 \mu$ l; (b) $200 \mu$ l; (c) 300 $\mu l ;$ (d) $500 \mu \mathrm{l} ;$ (e) $1,000 \mu \mathrm{l}$. 
addition to uniform hollow nanospheres, however, there were still some tiny particles, which were generated by direct reduction of minority metal ions not complexed with PVP. In Figures $2 \mathbf{c}, \mathbf{d}$, it can be found that the hollow-NiPt@SiO 2 core-shell structure catalyst is formed after $\mathrm{SiO}_{2}$ coating, and $\mathrm{SiO}_{2}$ also got the tiny particles in. The total particle size of the core-shell structure is about $50 \mathrm{~nm}$. As shown in Figures 2e,f, after calcination and reduction treatments, the hollow-NiPt NPs in the core-shell structure catalyst remained stable without any agglomeration. On the contrary, the hollow-NiPt NPs in the supported hollow$\mathrm{NiPt} / \mathrm{SiO}_{2}$ catalyst had partially aggregated. In addition, we also investigated the effect of TEOS addition on the morphology of the hollow-NiPt@SiO 2 core-shell catalyst as shown in Figure 3. When $150 \mu$ l TEOS was added, the particle size of the core-shell structure catlyst was about $50 \mathrm{~nm}$; when the amount of TEOS was increased to $200,300,500$, and $1,000 \mu l$, the particle size was about $100,120,135$, and $140 \mathrm{~nm}$, respectively. On the other hand, when only $100 \mu$ l TEOS was added, regular core-shell structure could not be formed. This shows that the TEOS concentration plays a significant role in determining the coating level (LizMarzán et al., 1996). However, an excessively thick $\mathrm{SiO}_{2}$ shell may lead to difficulty in reactants and products transfer in DRM reaction, resulting in the reaction activity decrease. Therefore, core-shell structure samples with a total particle size of $50 \mathrm{~nm}$ were selected for the following activity test to explore whether this thickness could be satisfied to keep hollow-NiPt NPs stable at high temperature.

In order to verify whether the hollow-alloy structure is superior to the solid-single metal structure, we prepared solid $\mathrm{Ni}$, solid $\mathrm{Pt}$, and solid $\mathrm{NiPt}$ alloy NPs, respectively. In addition, we also coated them with $\mathrm{SiO}_{2}$. For the activity comparison consistent, the particle size of all metal NPs is the same as that of hollow-NiPt, which is controlled at about $7 \mathrm{~nm}$. The thickness of $\mathrm{SiO}_{2}$ coating is the same as that of hollow-NiPt@SiO 2 , the total particle size is about $50 \mathrm{~nm}$. As shown in Figure 4, solid $\mathrm{Ni@SiO} 2, \mathrm{Pt} @ \mathrm{SiO}_{2}$, and alloy NiPt@SiO 2 catalysts were uniform core-shell structures with only one metal $\mathrm{NP}$ in one $\mathrm{SiO}_{2}$ shell. Besides, the
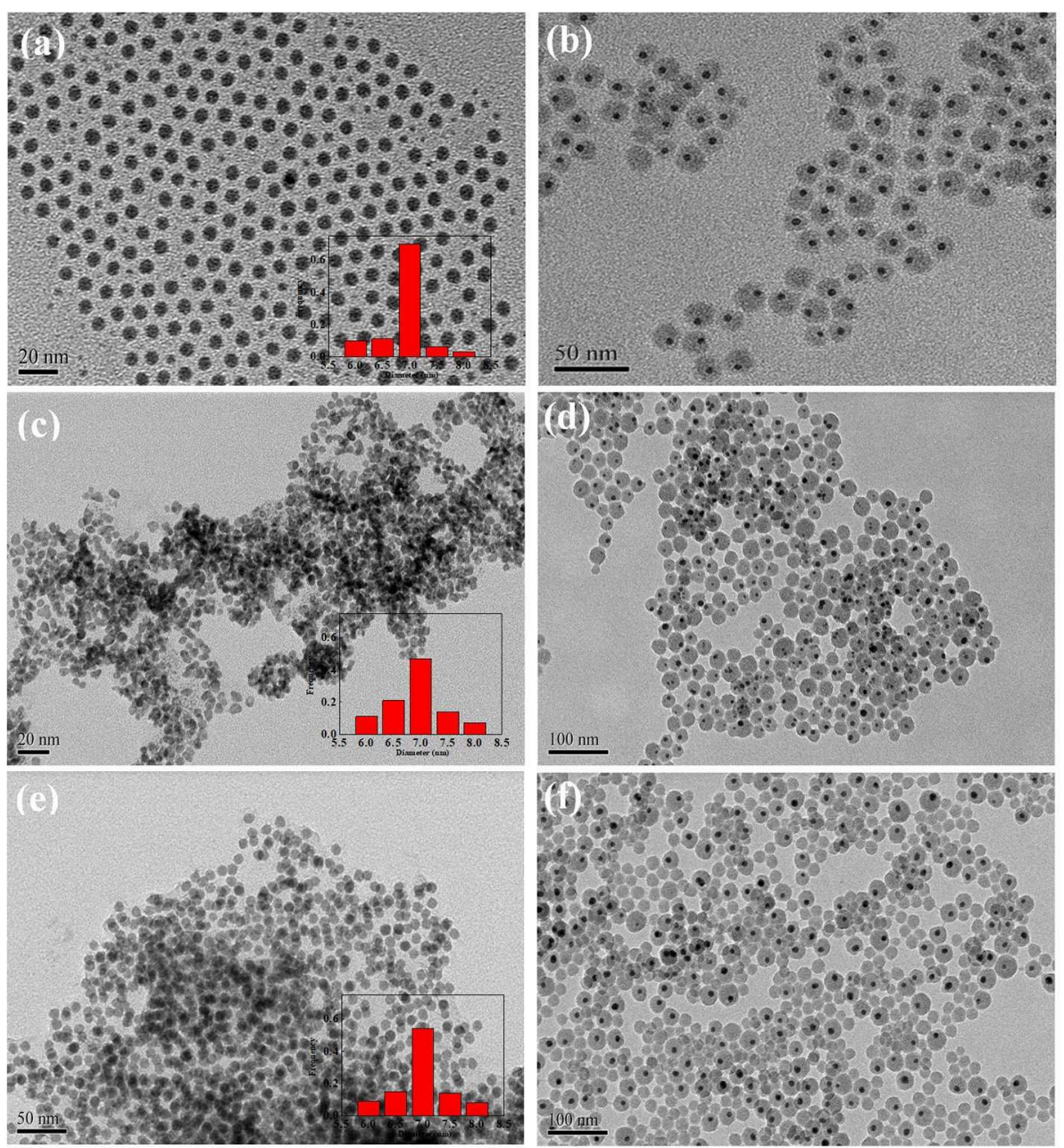

FIGURE 4 | Transmission electron microscopy (TEM) images of (a) Ni nanoparticles (NPs); (b) $\mathrm{Ni} @ \mathrm{SiO}_{2}$ before calcination; (c) Pt NPs; (d) Pt@SiO 2 before calcination; (e) NiPt NPs; and (f) NiPt@SiO 2 before calcination. The attached are the particle size distribution patterns. 
thermal stability of core-shell structures was also expressed in these three catalysts. After calcination, the core-shell structure remained unchanged, and the metal particles were not agglomerated.

The TPR profiles in Figure 5 revealed the reducibility of different catalysts. The reduction peaks of $\mathrm{Ni}$ and $\mathrm{Pt}$ oxides from calcination of $\mathrm{Ni}$ and Pt NPs were near 665 and $259^{\circ} \mathrm{C}$, respectively. After calcination, the hollow-NiPt catalyst had only a single reduction peak at $485^{\circ} \mathrm{C}$, which is between the reduction temperature of $\mathrm{Ni}$ and $\mathrm{Pt}$ oxides. We could speculate the formation of NiPt alloy in hollow-NiPt catalyst (Yu et al., 1997). It was worth noting that the reduction peak of solid NiPt oxides is in the same region as that of hollow-NiPt catalyst, indicating the formation of alloy in solid NiPt NPs. However, it splits into two peaks, 451 and $511^{\circ} \mathrm{C}$, respectively. If solid NiPt NP exists as alloy, the reduction peak must be the same as that of hollow-NiPt NPs. On the contrary, if it exists as a single metal, the reduction peak position must be the same as that of single metal $\mathrm{Ni}$ and single metal Pt. Therefore, the splitting of reduction peak demonstrates that solid NiPt NPs are in the intermediate state of single metal and alloy, which manifests that parts of solid NiPt particles are still in the form of single $\mathrm{Ni}$ and Pt.

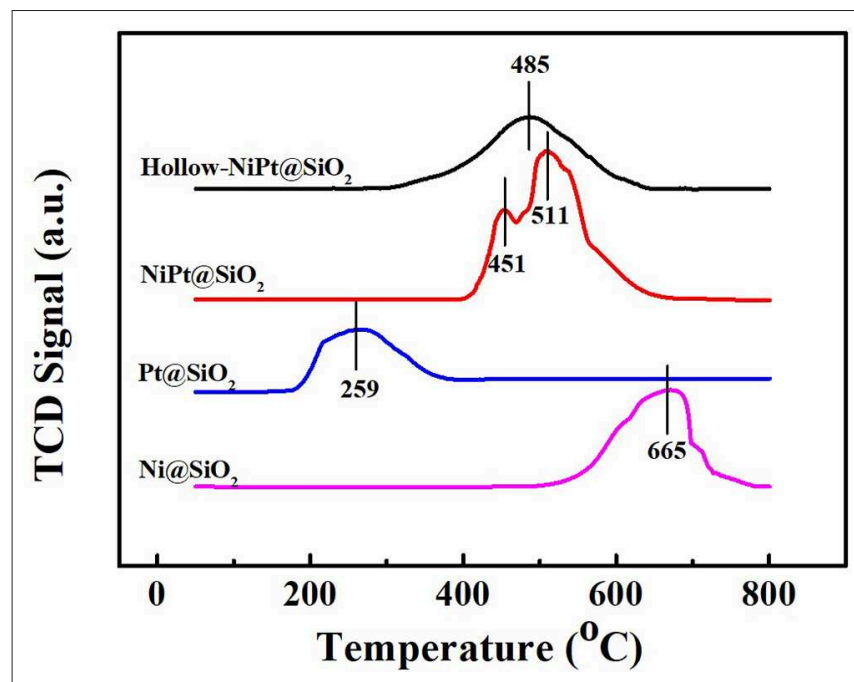

FIGURE 5 | Temperature programmed reduction (TPR) spectras of different catalysts. TCD, thermal conductivity detector.

\section{Catalytic Performance and Stability Test}

In order to guarantee the comparability of all test results, the metal content of catalyst in each activity test was constant, which is $0.085 \mathrm{mmol}$. We can see from Table 1 that the hollow$\mathrm{NiPt@SiO} 2$ core-shell catalyst shows the highest initial $\mathrm{CH}_{4}$ and $\mathrm{CO}_{2}$ conversion compared with other catalysts. In addition, the activity was related to the metal dispersion of the catalyst, because the catalytic reaction takes place on the surface of the active site. This is because all catalytic reactions take place on the catalyst surface, which means that the more active sites exposed to the catalyst surface, the more active sites can participate in the reaction, thus it has higher activity. Nevertheless, with the same NiPt active site, the initial activity of core-shell catalyst was higher than that of the supported catalyst. This may be related to the dispersion state of the reduced hollow NiPi NPs. It can be seen from the TEM in Figure $\mathbf{2 f}$ that some NPs agglomerate in the supported catalyst after reduction, which did not appear in the core-shell catalyst (Figure 2e). The aggregation of particles reduced the metal dispersion, thus reducing the utilization of the active sites of the catalyst and ultimately reducing the activity of the catalyst.

Compared with solid core-shell catalysts, hollow-NiPt catalysts had higher metal dispersion and $\mathrm{CH}_{4} / \mathrm{CO}_{2}$ conversions. This is due to the fact that the hollow structure has both internal and external reaction surfaces, which increases the contact point between reactants and active sites and thus improves the availability of noble metal Pt. In solid core-shell catalysts, the activity decreased in the order: $\mathrm{NiPt}>\mathrm{Pt}>\mathrm{Ni}$, and the activity of Pt was only slightly higher than that of $\mathrm{Ni}$, while the NiPt alloy possessed a large superiority over $\mathrm{Pt}$ or $\mathrm{Ni}$. The result showed that the catalytic DRM reaction activity of $\mathrm{Ni}$ is comparable to that of $\mathrm{Pt}$ at high temperature. The electron transfer between the metals in the alloy catalyst makes the $\mathrm{CH}_{4} / \mathrm{CO}_{2}$ have a higher activation efficiency at the active site and thus have a higher reaction activity, which is also proved by our results.

We were surprised to find that the $\mathrm{CH}_{4}$ conversion is a little bit higher than $\mathrm{CO}_{2}$ conversion only when the hollow-NiPt catalysts are used, yet it is the opposite in solid catalysts which may be explained by the reverse water gas shift (RWGS) reaction $\left(\mathrm{CO}_{2}+\mathrm{H}_{2} \rightarrow \mathrm{CO}+\mathrm{H}_{2} \mathrm{O}\right)$ (Goguet et al., 2004). So we got the conclusion that hollow-NiPt catalysts can effectively reduce the RWGS reaction, thus reducing the generation of by-product $\mathrm{H}_{2} \mathrm{O}$ and improving the selectivity of syngas.

According to the ICP analysis, the metal loadings in the coreshell and supported hollow-NiPt catalysts were determined as

TABLE 1 | Structural and catalytic parameters of different catalysts ${ }^{\mathrm{a}}$.

\begin{tabular}{|c|c|c|c|c|c|}
\hline Catalysts & Hollow-NiPt@SiO 2 & $\mathrm{Ni@SiO} 2$ & $\mathrm{Pt@SiO}$ & ${\mathrm{NiPt} @ \mathrm{SiO}_{2}}_{2}$ & Hollow-NiPt/SiO ${ }_{2}$ \\
\hline Metal loading (wt.\%) & 8.7 & 13.8 & 18.9 & 16.2 & 9.1 \\
\hline $\mathrm{CO}$ adsorption $(\mu \mathrm{mol} / \mathrm{g}$ metal $)$ & 1,597 & 1,107 & 1,159 & 1,143 & 1,440 \\
\hline Metal dispersion (\%) & 22.6 & 15.6 & 16.3 & 16.1 & 20.3 \\
\hline $\mathrm{CH}_{4}$ conversion (\%) & 97.1 & 87.0 & 88.7 & 90.1 & 94.9 \\
\hline $\mathrm{CO}_{2}$ conversion (\%) & 96.5 & 87.9 & 89.3 & 91.3 & 94.8 \\
\hline
\end{tabular}

${ }^{a}$ Reaction conditions: $800^{\circ} \mathrm{C}, \mathrm{CH}_{4}: \mathrm{CO}_{2}: \mathrm{N}_{2}=1: 1: 1$, Gaseous Hourly Space Velocity $=600 \mathrm{~L} \cdot \mathrm{g}_{M}^{-1} \cdot \mathrm{h}^{-1}$. 
A

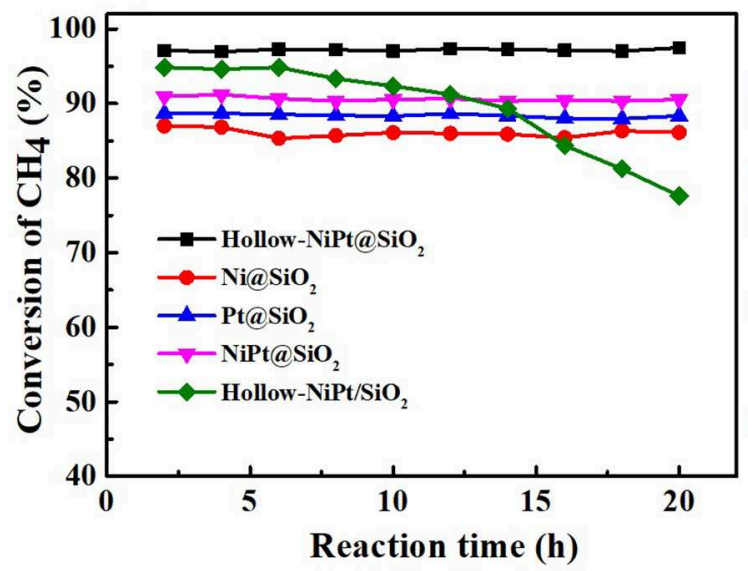

B

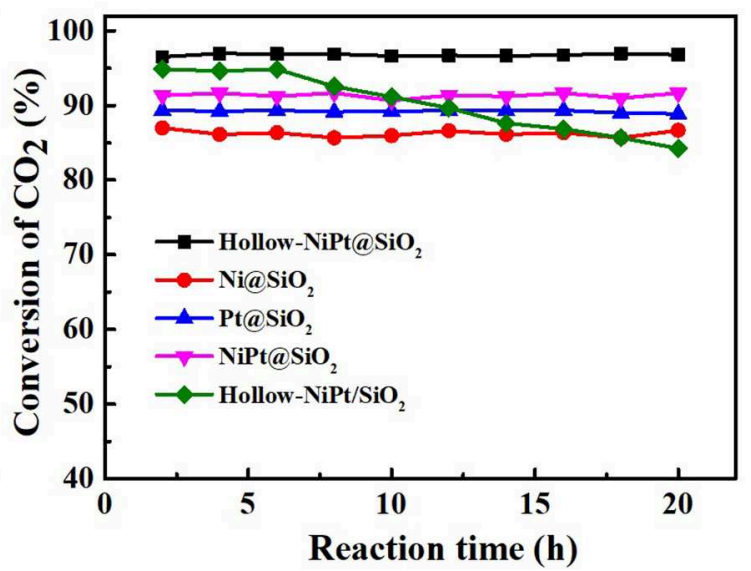

FIGURE 6 | Stability test of all catalysts. (A) $\mathrm{CH}_{4}$ conversion, (B) $\mathrm{CO}_{2}$ conversion. Reaction conditions: $800^{\circ} \mathrm{C}, \mathrm{CH}_{4}: \mathrm{CO}_{2}: \mathrm{N}_{2}=1: 1: 1$, Gaseous Hourly Space Velocity $=600 \mathrm{~L} \cdot \mathrm{g}_{\mathrm{M}}^{-1} \cdot \mathrm{h}^{-1}$.

8.7 wt. and $9.1 \%$, which is significantly lower than that in solid catalysts because the hollow NPs have a smaller density and the mass of hollow NPs will be smaller than that of solid NPs with the same size. Similarly, in these solid catalysts, the total metal loading of the catalysts containing the denser Pt was higher.

The best way to determine whether the catalyst is suitable for continuous and stable operations in such a high temperature is to use the DRM reaction to investigate its catalytic stability. We tested the activities of all core-shell and supported structure catalysts with Gaseous Hourly Space Velocity of $600 \mathrm{~L} \cdot \mathrm{g}_{\mathrm{M}}^{-1} \cdot \mathrm{h}^{-1}$. As shown in Figure 6, within $20 \mathrm{~h}$, all core-shell catalysts maintained the same activity, while the $\mathrm{CH}_{4}$ and $\mathrm{CO}_{2}$ conversion of supported hollow- $\mathrm{NiPt} / \mathrm{SiO}_{2}$ decreased from 94.9 to $77.6 \%$ and 94.8 to $84.3 \%$, respectively. It can be found that after $20 \mathrm{~h}$ reaction, the $\mathrm{CO}_{2}$ conversion of hollow-NiPt/SiO 2 catalyst was significantly higher than that of $\mathrm{CH}_{4}$. There may be two reasons here, one is RWGS reaction, the other is the generated carbon deposit, which reacts with $\mathrm{CO}_{2}$ to produce $\mathrm{CO}$. The reason why hollow-NiPt@SiO 2 has better stability than hollow-NiPt/SiO ${ }_{2}$ is that the core-shell structure has better ability to protect metal active sites than the support structure at high temperature, thus reducing the probability of $\mathrm{CO}$ disproportionation. The activity of hollow-NiPt@SiO $\mathrm{S}_{2}$ catalysts was higher than that of hollow- $\mathrm{NiPt} / \mathrm{SiO}_{2}$ catalysts due to the metal dispersion of catalyst decreases caused by the agglomeration of particles. Figure 7 also reveals the long-term stability test of hollow-NiPt@SiO 2 catalysts, which can keep stable for $200 \mathrm{~h}$ without any $\mathrm{CH}_{4}$ and $\mathrm{CO}_{2}$ conversion change. This indicates that the $\mathrm{SiO}_{2}$-coated hollow-NiPt core-shell catalyst has a considerable industrial application prospect.

In order to investigate the cause for the divergence of stability between core-shell catalyst and supported catalyst, we characterized the catalysts after $20 \mathrm{~h}$ reaction. As shown in Figure 8a, TEM images proclaim that hollow-NiPt@SiO $\mathrm{S}_{2}$ catalyst still holds its original core-shell structure after reaction, without

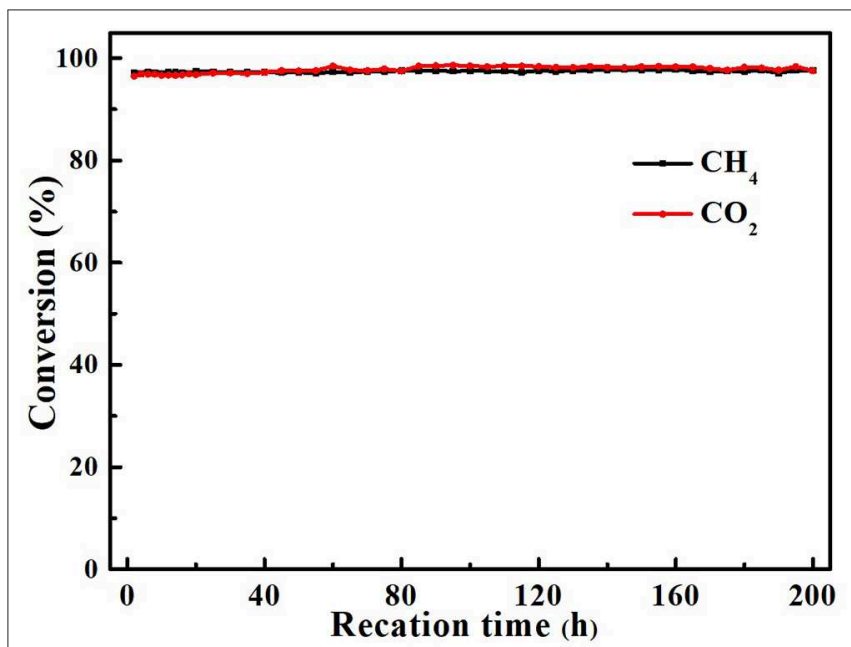

FIGURE 7 | Stability test for Hollow-NiPt@SiO 2 core-shell catalyst. Reaction conditions: $800^{\circ} \mathrm{C}, \mathrm{CH}_{4}: \mathrm{CO}_{2}: \mathrm{N}_{2}=1: 1: 1$, Gaseous Hourly Space Velocity = $600 \mathrm{~L} \cdot \mathrm{g}_{\mathrm{M}}^{-1} \cdot \mathrm{h}^{-1}$.

evident active site aggregation and carbon deposition. Instead, the hollow-NiPt NPs in the supported catalyst in Figure $\mathbf{8 b}$ agglomerate seriously, and the $\mathrm{SiO}_{2}$ nanospheres change to the carrier without a certain shape. It is aware that water will partially dissociate at high temperature, producing generous $\mathrm{H}^{+}$and $\mathrm{OH}^{-} \cdot \mathrm{OH}^{-}$will react with $\mathrm{SiO}_{2}$, thus destroying the morphology of $\mathrm{SiO}_{2}$ nanospheres. After reduction, some hollow-NiPt NPs on the supported catalysts agglomerate, which promotes the generation of by-product $\mathrm{H}_{2} \mathrm{O}$, thus destroying the $\mathrm{SiO}_{2}$ morphology, further sintering NPs, forming a vicious cycle (Keulen et al., 1997).

The thermogravimetric (TG) profile in Figure 8c illustrated that hollow-NiPt@SiO 2 catalysts produce no carbon deposit after reaction at $800^{\circ} \mathrm{C}$ for $20 \mathrm{~h}$, but the weight loss of 

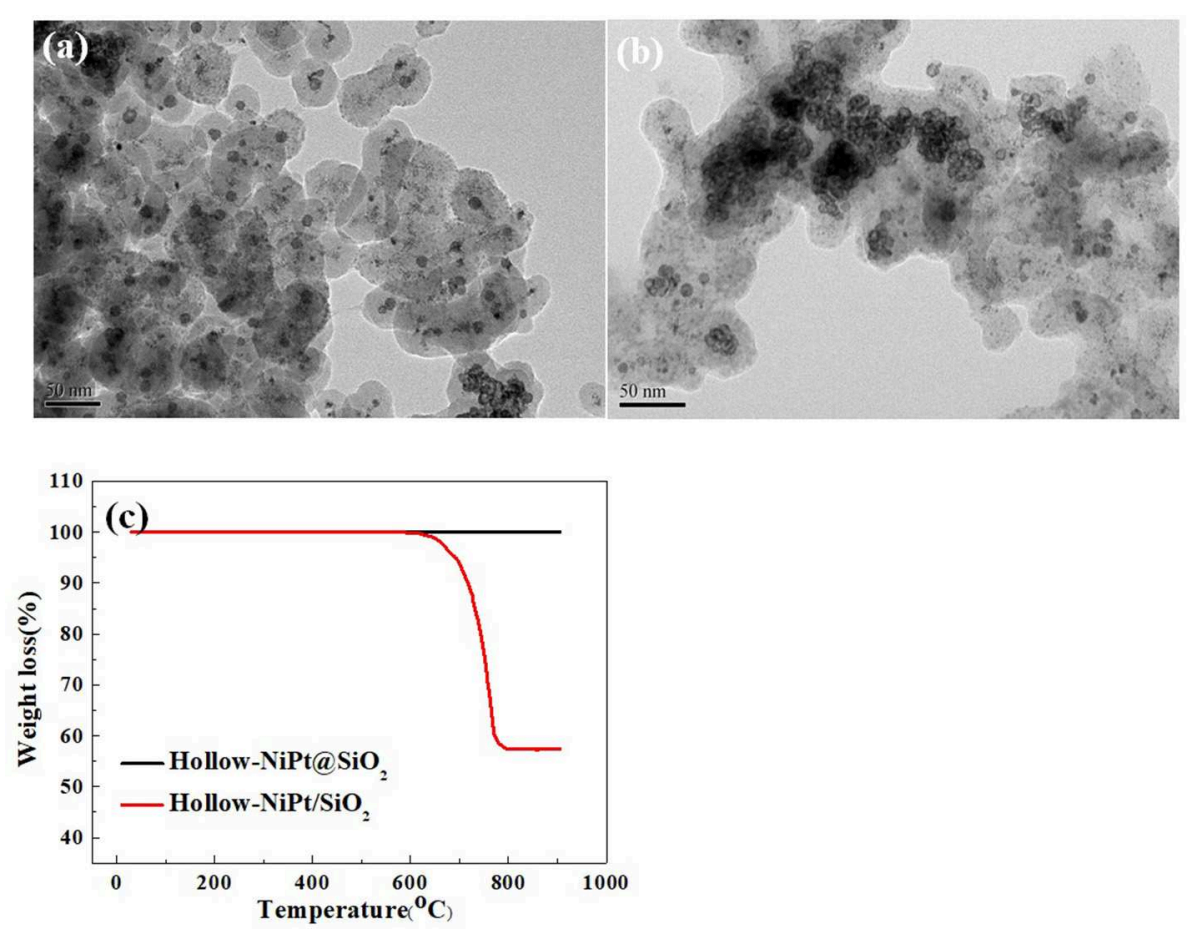

FIGURE 8 | Characterizations of core-shell catalyst and supported catalyst after dry reforming of methane $\left(\mathrm{CH}_{4}\right)(\mathrm{DRM})$ reaction at $800^{\circ} \mathrm{C}$ for $20 \mathrm{~h}$. (a) Transmission electron microscopy (TEM) image of Hollow-NiPt@SiO ${ }_{2}$, (b) TEM image of Hollow- $\mathrm{NiPt} / \mathrm{SiO}_{2}$, (c) Thermogravimetric patterns. Reaction conditions: $800^{\circ} \mathrm{C}$, $\mathrm{CH}_{4}: \mathrm{CO}_{2}: \mathrm{N}_{2}=1: 1: 1$, Gaseous Hourly Space Velocity $=600 \mathrm{~L} \cdot \mathrm{g}_{\mathrm{M}}^{-1} \cdot \mathrm{h}^{-1}$.

hollow- $\mathrm{NiPt} / \mathrm{SiO}_{2}$ catalyst was about $20 \%$ in the process of heating up. The temperature range of weight loss was about $600-800^{\circ} \mathrm{C}$, corresponding to the process of carbon deposit elimination (Yu et al., 2013). There is no obvious carbon crystal lattice in TEM, but this is not the evidence of no carbon deposition because the carbon deposit may exist in the form of amorphous.

\section{CONCLUSIONS}

In conclusion, we prepared an original hollow-NiPt@SiO 2 catalyst for the first time, which took hollow-NiPt as the core and encapsulated it in an inert $\mathrm{SiO}_{2}$ shell with a classic TEOS hydrolysis method. A series of core-shell materials with different $\mathrm{SiO}_{2}$ thicknesses were obtained by adjusting the amount of TEOS. In the reaction of $\mathrm{CH}_{4} / \mathrm{CO}_{2}$ converted to syngas by DRM reaction, such hollow-NiPt catalysts had considerable activity advantages compared with solid $\mathrm{Ni}$, Pt, or $\mathrm{NiPt}$ alloy. The conversion of $\mathrm{CH}_{4}$ and $\mathrm{CO}_{2}$ can be close to $100 \%$. Furthermore, the catalyst had very good thermal stability and can run stably at $800^{\circ} \mathrm{C}$ for more than $200 \mathrm{~h}$. By comparing the stability of coreshell catalysts and supported catalysts, we got a conclusion that $\mathrm{SiO}_{2}$ can keep hollow-NiPt constancy in DRM reaction at high temperature. At the beginning of the reaction, hollow-NiPt in the supported catalyst began to agglomerate and generate carbon deposit, which showed continuous deactivation. Compared with different solid metal core-shell catalysts, hollow-NiPt@SiO 2 had pretty good activity due to its double reaction surfaces and alloy effect. On balance, this work provides a strategy for stabilizing the hollow metal material, and the composite material can be used for high temperature reaction.

\section{DATA AVAILABILITY STATEMENT}

All datasets generated for this study are included in the article/supplementary material.

\section{AUTHOR CONTRIBUTIONS}

Specifically, HL and YZ proposed this topic and design of the project. YL completed the characterization part. GW completed the experimental part. YZ analyzed the results. JS and GW composed the manuscript. All authors participated in the discussions of the results and made important contributions on this work.

\section{FUNDING}

This work was supported by the National Natural Science Foundation of China (21972093), the Ministry of Education of China (PCSIRT_IRT_16R49), and the Shanghai Engineering Research Center of Green Energy Chemical Engineering (18DZ2254200). 


\section{REFERENCES}

Amin, R., Chang, X. Q., and Liu, B. S. (2017). Synergistic effect of $\mathrm{CeO}_{2}$ in $\mathrm{CH}_{4} / \mathrm{CO}_{2}$ dry reforming reaction over stable $\mathrm{xCeO}_{2} \mathrm{yNi} / \mathrm{MCM}-22$ catalysts. Ind. Eng. Chem. Res. 56, 7445-7453. doi: 10.1021/acs.iecr.7b01375

Bian, Z. F., Suryawinata, I. Y., and Kawi, S. (2016). Highly carbon resistant multicore-shell catalyst derived from Ni-Mg phyllosilicate nanotubes@silica for dry reforming of methane. Appl. Catal. B-Environ. 195, 1-8. doi: 10.1016/j.apcatb.2016.05.001

Chen, G., Xia, D. G., Nie, Z. R., Wang, Z. Y., Wang, L., Zhang, L., et al. (2007). Facile synthesis of Co-Pt hollow sphere electrocatalyst. Chem. Mater. 19, 1840-1844. doi: $10.1021 / \mathrm{cm} 062336 \mathrm{z}$

Chen, J. C., Zhang, R. Y., Han, L., Tu, B., and Zhao, D. Y. (2013). One-pot synthesis of thermally stable gold@mesoporous silica core-shell nanospheres with catalytic activity. Nano Res. 6, 871-879. doi: 10.1007/s12274-013-0363-1

Chen, X. Y., Wang, W. L., Wang, S., Qiao, M. H., Yan, S. R., Fan, K. N., et al. (2005). Amorphous Ni-B hollow spheres synthesized by controlled organization of $\mathrm{Ni}-$ B nanoparticles over PS beads via surface seeding/electroless plating. New J. Chem. 29, 266-268. doi: 10.1039/B411261J

Djinović, P., Crnivec, I. G. O., Erjavec, B., and Pintar, A. (2012). Influence of active metal loading and oxygen mobility on coke-free dry reforming of Ni-Co bimetallic catalysts. Appl. Catal. B-Environ. 125, 259-270. doi: $10.1016 /$ j.apcatb.2012.05.049

García-Diéguez, M., Pieta, I. S., Herrera, M. C., Larrubia, M. A., and Alemany, L. J. (2010). Nanostructured Pt-and Ni-based catalysts for $\mathrm{CO}_{2}$-reforming of methane. J. Catal. 270, 136-145. doi: 10.1016/j.jcat.2009.12.010

Goguet, A., Meunier, F., Breen, J. P., Burch, R., Petch, M. I., and Ghenciuc, A. F. (2004). Study of the origin of the deactivation of a $\mathrm{Pt} / \mathrm{CeO}_{2}$ catalyst during reverse water gas shift (RWGS) reaction. Nano Res. 226, 382-392. doi: 10.1016/j.jcat.2004.06.011

Graf, P. O., Mojet, B. L., Ommen, J. G., and Lefferts, L. (2007). Comparative study of steam reforming of methane, ethane and ethylene on Pt, Rh and Pd supported on yttrium-stabilized zirconia. Appl. Catal. A-Gen. 332, 310-317. doi: 10.1016/j.apcata.2007.08.032

Guczi, L., Stefler, G., Geszti, O., Saj,ó, I., Pászti, Z., Tompos, A., et al. (2010). Methane dry reforming with $\mathrm{CO}_{2}$ : a study on surface carbon species. Appl. Catal. A-Gen. 375, 236-246. doi: 10.1016/j.apcata.2009.12.040

Guo, J. J., Lou, H., Zhao, H., Chai, D. F., and Zheng, X. M. (2004). Dry reforming of methane over nickel catalysts supported on magnesium aluminate spinels. Appl. Catal. A-Gen. 273, 75-82. doi: 10.1016/j.apcata.2004.06.014

Gurney, K. R., Mendoza, D. L., Zhou, Y. Y., Fischer, M. L., Miller, C. C., Geethakumar, S., et al. (2009). High resolution fossil fuel combustion $\mathrm{CO}_{2}$ emission fluxes for the United States. Environ. Sci. Technol. 43, 5535-5541. doi: $10.1021 / \mathrm{es} 900806 \mathrm{c}$

Iulianelli, A., Liguori, S., Wilcox, J., and Basile, A. (2016). Advances on methane steam reforming to produce hydrogen through membrane reactors technology: a review. Catal. Rev. 58, 1-35. doi: 10.1080/01614940.2015.1099882

Keulen, A. N. J. V., Seshan, K., Hoebink, J. H. B. J., and Ross, J. R. H. (1997). TAP Investigations of the $\mathrm{CO}_{2}$ Reforming of $\mathrm{CH}_{4}$ over $\mathrm{Pt} / \mathrm{ZrO}_{2}$. J. Catal.166, 306-314. doi: 10.1006/jcat.1997.1539

Kim, S. K., Kim, M., Li, W. Y., and Hyeon, T. (2002). Fabrication of hollow palladium spheres and their successful application to the recyclable heterogeneous catalyst for Suzuki coupling reactions. J. Am. Chem. Soc. 124, 7642-7643. doi: 10.1021/ja026032z

Li, H., Lin, H., Hu, Y., Li, H. X., Li, P., and Zhou, X. G. (2011). Hollow Pt-Ni alloy nanospheres with tunable chamber structure and enhanced activity. J. Mater. Chem. 21, 18447-18453. doi: 10.1039/c1jm11461a

Li, H., Liu, J., Xie, S. H., Qiao, M. H., Dai, W. L., Lu, Y. F., et al. (2008). Vesicle-assisted assembly of mesoporous Ce-doped Pd nanospheres with a hollow chamber and enhanced catalytic efficiency. J. Biol. Chem. 18, 3235-3241. doi: $10.1002 / \mathrm{adfm} .200800667$

Li, H., Zhang, D. Q., Li, G. S., Xu, Y., Lu, Y. F., and Li, H. X. (2010). Mesoporous Ni$\mathrm{B}$ amorphous alloy microspheres with tunable chamber structure and enhanced hydrogenation activity. Chem. Commun. 46, 791-793. doi: 10.1039/B917430C

Li, Y. G., Zhou, P., Dai, Z. H., Hu, Z. X., Sun, P. P., and Bao, J. C. (2006). A facile synthesis of PdCo bimetallic hollow nanospheres and their application to Sonogashira reaction in aqueous media. New J. Chem. 30, 832-837. doi: $10.1039 / \mathrm{B} 604581 \mathrm{M}$
Liu, D. P., Cheo, W. N. E., Lim, Y. W. Y., Borgna, A., Lau, R., and Yang, Y. H. (2010). A comparative study on catalyst deactivation of nickel and cobalt incorporated MCM-41 catalysts modified by platinum in methane reforming with carbon dioxide. Catal. Today 154, 229-236. doi: 10.1016/j.cattod.2010.03.054

Liz-Marzán, L. M., Giersig, M., and Mulvaney, P. (1996). Synthesis of nanosized gold-silica core-shell particles. Langmuir 12, 4329-4335. doi: 10.1021/la9601871

Michael, G., Jae, E., Patrick, B., and Michael, M. (1993). The costs of limiting fossilfuel $\mathrm{CO}_{2}$ emissions: a survey and analysis. Annu. Rev. Energ. Env. 18, 397-478. doi: 10.1146/annurev.eg.18.110193.002145

Middleton, R. S., Gupta, R., Hyman, J. D., and Viswanathan, H. S. (2017). The shale gas revolution: barriers, sustainability, and emerging opportunities. Appl. Energy 199, 88-95. doi: 10.1016/j.apenergy.2017.04.034

Miura, S., Fujisawa, A., and Ishida, M. (2012). A hydrogen purification and storage system using metal hydride. Int. J. Hydrog. Energy 37, 2794-2799. doi: 10.1016/j.ijhydene.2011.03.150

Miura, S., Fujisawa, A., Tomekawa, S., Taniguchi, Y., Hanada, N., and Ishida, M. (2013). A hydrogen purification and storage system using CO adsorbent and metal hydride. J. Alloy. Compd. 580, S414-S417. doi: 10.1016/j.jallcom.2013.03.154

Nagaoka, K., Okamura, M., and Aika, K. (2001b). Titania supported ruthenium as a coking-resistant catalyst for high pressure dry reforming of methane. Catal. Commun. 2, 255-260. doi: 10.1016/S1566-7367(01)00043-7

Nagaoka, K., Seshan, K., Aika, K., and Lercher, J. A. (2001a). Carbon deposition during carbon dioxide reforming of methane-comparison between $\mathrm{Pt} / \mathrm{Al}_{2} \mathrm{O}_{3}$ and $\mathrm{Pt} / \mathrm{ZrO}_{2}$. J. Catal. 197, 34-42. doi: 10.1006/jcat.2000.3062

Nagaoka, K., Takanabe, K., and Aika, K. (2003). Influence of the reduction temperature on catalytic activity of $\mathrm{Co} / \mathrm{TiO}_{2}$ (anatase-type) for high pressure dry reforming of methane. Appl. Catal. A-Gen. 255, 13-21. doi: 10.1016/S0926-860X(03)00631-8

Nowosielska, M., Jozwiak, W. K., and Rynkowski, J. (2009). Physicochemical characterization of $\mathrm{Al}_{2} \mathrm{O}_{3}$ supported $\mathrm{Ni}-\mathrm{Rh}$ systems and their catalytic performance in $\mathrm{CH}_{4} / \mathrm{CO}_{2}$ reforming. Catal. Lett. 128, 83-93. doi: 10.1007/s10562-008-9737-5

Otsuka, K., Said, A. A., Jinno, K., and Komatsu, T. (1987). Peroxide anions as possible active species in oxidative coupling of methane. Chem. Lett. 16, 77-80. doi: 10.1246/cl.1987.77

Özkara-Aydinoglu, A., Özensoy, E., and Aksoylua, A. E. (2009). The effect of impregnation strategy on methane dry reforming activity of $\mathrm{Ce}$ promoted $\mathrm{Pt} / \mathrm{ZrO}_{2}$. Int. J. Hydrog. Energy 34, 9711-9722. doi: 10.1016/j.ijhydene.2009.09.005

Parola, V. A., Pantaleo, G., Deganello, F., Bal, R., and Venezia, A. M. (2018). Plain and $\mathrm{CeO}_{2}$-supported $\mathrm{La}_{\mathrm{x}} \mathrm{NiO}_{\mathrm{y}}$ catalysts for partial oxidation of $\mathrm{CH}_{4}$. Catal. Today 307, 189-196. doi: 10.1016/j.cattod.2017.04.045

Qiao, B. T., Wang, A. Q., Yang, X. F., Allard, L. F., Jiang, Z., Cui, Y. T., et al. (2011). Single-atom catalysis of $\mathrm{CO}$ oxidation using $\mathrm{Pt}_{1} / \mathrm{FeO}_{\mathrm{x}}$. Nat. Chem. 3, 634-641. doi: 10.1038/NCHEM.1095

Qiu, B., Yang, C., Guo, W. H., Xu, Y., Liang, Z. B., Ma, D., et al. (2017). Highly dispersed Co-based Fischer-Tropsch synthesis catalysts from metal-organic frameworks. J. Mater. Chem. A 5, 8081-8086. doi: 10.1039/C7TA02128C

Radloff, C., and Halas, N. J. (2001). Enhanced thermal stability of silica-encapsulated metal nanoshells. Appl. Phys. Lett. 79, 674-676. doi: $10.1063 / 1.1389322$

Reddy, P. V. L., Kim, K. H., and Song, H. (2013). Emerging green chemical technologies for the conversion of $\mathrm{CH}_{4}$ to value added products. Renew. Sust. Energ. Rev. 24, 578-585. doi: 10.1016/j.rser.2013.03.035

Rosli, R. E., Sulong, A. B., Daud, W. R. W., Zulkifley, M. A., Husaini, T., Rosli, M. I., et al. (2017). A review of high-temperature proton exchange membrane fuel cell (HT-PEMFC) system. Int. J. Hydrog. Energy 42, 9293-9314. doi: 10.1016/j.ijhydene.2016.06.211

Sun, N. J., and Klabunde, K. J. (1999). Nanocrystal metal oxide-chlorine adducts: selective catalysts for chlorination of alkanes. J. Am. Chem. Soc. 121, 5587-5588. doi: 10.1021/ja990084f

Wang, N., Chu, W., Zhang, T., and Zhao, X. S. (2011). Manganese promoting effects on the Co-Ce-Zr- $\mathrm{O}_{\mathrm{x}}$ nano catalysts for methane dry reforming with carbon dioxide to hydrogen and carbon monoxide. Chem. Eng. J. 170, 457-463. doi: 10.1016/j.cej.2010.12.042 
Wu, K. L., Chen, Z. C., Li, X. F., Guo, C. H., and Wei, M. Z. (2016). A model for multiple transport mechanisms through nanopores of shale gas reservoirs with real gas effect-adsorption-mechanic coupling. Int. J. Heat Mass Transf. 93, 408-426. doi: 10.1016/j.ijheatmasstransfer.2015.10.003

Yu, D. W., Zhu, M. Q., Utigard, T. A., and Barati, M. (2013). TGA kinetic study on the hydrogen reduction of an iron nickel oxide. Miner. Eng. 54, 32-38. doi: 10.1016/j.mineng.2013.03.018

Yu, Z. B., Qiao, M. H., Li, H. X., and Deng, J. F. (1997). Preparation of amorphous $\mathrm{NiCoB}$ alloys and the effect of cobalt on their hydrogenation activity. Appl. Catal. A-Gen. 163, 1-13. doi: 10.1016/S0926-860X(96)00419-X

Zhang, R. G., Duan, T., Ling, L. X., and Wang, B. J. (2015). $\mathrm{CH}_{4}$ dehydrogenation on Cu (1 11 1), $\mathrm{Cu} @ \mathrm{Cu}\left(\begin{array}{lll}1 & 1 & 1\end{array}\right), \mathrm{Rh} @ \mathrm{Cu}\left(\begin{array}{lll}1 & 1 & 1\end{array}\right)$ and $\mathrm{RhCu}\left(\begin{array}{lll}1 & 1 & 1\end{array}\right)$ surfaces: a comparison studies of catalytic activity. Appl. Surf. Sci. 30, 100-108. doi: 10.1016/j.apsusc.2015.03.013

Zhao, Y., Kang, Y. Q., Li, H., and He, H. Y. (2018a). $\mathrm{CO}_{2}$ conversion to synthesis gas via DRM on the durable $\mathrm{Al}_{2} \mathrm{O}_{3} / \mathrm{Ni} / \mathrm{Al}_{2} \mathrm{O}_{3}$ sandwich catalyst with high activity and stability. Green Chem. 20, 2781-2787. doi: 10.1039/C8GC0 $0743 \mathrm{H}$

Zhao, Y., Li, H., and He, H. Y. (2018b). NiCo@SiO 2 core-shell catalyst with high activity and long lifetime for $\mathrm{CO}_{2}$ conversion through
DRM reaction. Nano Energy 45, 101-108. doi: 10.1016/j.nanoen.2017. 12.023

Zhou, P., Li, Y. G., Sun, P. P., Zhou, J. H., and Bao, J. C. (2007). A novel Heck reaction catalyzed by Co hollow nanospheres in ligand-free condition. Chem. Commun. 14, 1418-1420. doi: 10.1039/B617556B

Conflict of Interest: Authors GW, YL, JS and JZ were employed by company Anhui Yuanchen Environmental Protection Technology Co., Ltd.

The remaining author declares that the research was conducted in the absence of any commercial or financial relationships that could be construed as a potential conflict of interest.

Copyright (c) 2020 Wang, Liang, Song, Li and Zhao. This is an open-access article distributed under the terms of the Creative Commons Attribution License (CC BY). The use, distribution or reproduction in other forums is permitted, provided the original author(s) and the copyright owner(s) are credited and that the original publication in this journal is cited, in accordance with accepted academic practice. No use, distribution or reproduction is permitted which does not comply with these terms. 